\title{
Reduction of Fine Iron Ores in Gas Conveyed Systems*
}

\author{
By Masaya OZAWA** and Minoru TANAKA**
}

\begin{abstract}
Synopsis
Finely powdered iron ores generally show a high reaction rate because of their large reaction surface. In order to take advantage of this property, a gas conveyed system was applied to the reduction of finely powdered iron ores, and feasibility of the process was studied. Hydrogen reduction of very fine powder of pyrite cinder, which had been very difficult to treat by fluidized bed, was successful by this way, and the capacity of processing seemed to be larger than that of fluidized bed process in the case of similar effective volume. Hydrogen reduction of fine iron ores by the gas conveyed system was largely affected by water vapor formed during the reduction. Reduction of fine hematite ores in a very dilute phase was studied and the relations between the rate constant and the water vapor pressure were determined. From these relations, a rate equation for high solid/gas ratios was derived. It was shown that this equation was valid for relatively concentrated solid gas systems.
\end{abstract}

\section{Introduction}

Fluidized bed reduction is considered as the suitable process for the treatment of fine iron ores which are not agglomerated by pelletizing or sintering. However, it is not only hard to fluidize very fine iron ores but also difficult to supply a sufficient amount of reducing gas for the promotion of reaction even in the case that this process is possibly applied, because the smaller the particle size is, the less gas velocity must be applied to keep good fluidization. Besides, at high temperature reduction, sintering or coagulation may cause the defluidization, and this tendency becomes stronger for finer iron ores.

Fluidized bed reduction of very fine iron ores accompanies various problems. If these problems are solved, a very effective reduction process may be established because of its very high reaction rate. Taking this into consideration, we studied the fine iron ore reduction in a gas conveyed system.

Gas conveyed systems have been utilized to pneumatic conveying of corn, cement, ore and preheating or drying of powder, circulation or transport of catalyst and a dilute phase fluidized bed reaction. ${ }^{1)}$ Flush roaster for sulfide ores may be regarded as a type of reactor based on the gas conveyed system.

As to reduction of fine iron ores, Lloyed and Amudson $^{2}$ ) investigated the hydrogen reduction of pigment grade iron oxide and Taconite concentrate (magnetite) in a Vycor glass tube of $25 \mathrm{~mm} \phi$ and $2.7 \mathrm{~m} \mathrm{long}$, and showed that at a temperature above $450^{\circ} \mathrm{C}$, it came up to $90 \%$ reduction in a period of 2 to $15 \mathrm{sec}$. They proposed that a cross-examination on the characteristic of single particle reduction process of iron ore can be made by this method when a few oxide particles are entrained in a relatively large amount of hydrogen.
Dalla Lana and Amundson ${ }^{3)}$ also studied the reduction of iron oxide with a size distribution ranging from 2 to 22 micron in a reactor made of a stainless steel pipe (type 304) of 2 in. diameter and $26 \mathrm{ft}$. long.

In this experiments, a vertical tubular reactor was used and solid-gas mixtures were transported upward through the reactor. In contrast to this, Themelis and Gauvin ${ }^{4}$ studied the reduction of spherical particles of iron oxide in gas conveyed systems, in which the reaction proceeded through the downward flow of solid-gas mixture, and also the kinetics of gas reduction of fine particles.

Most of these researches aimed at studying the reduction behavior of fine iron oxide in a very dilute phase of solid-gas mixture simulating a single particle reduction. Dalla Lana et al. tried to scale up this process but they did not clarify the effect of the ore feeding rate on the rate of reaction.

We have reported elsewhere ${ }^{5)}$ about the studies on the movement of ore particles in a gas conveyed system and the reduction behavior of fine pyrite cinder in a very dilute phase.

In this paper we deal with the effect of water vapor on the hydrogen reduction and the reduction behavior of fine iron ore when the solid feeding rate is somewhat increased in a gas conveyed system, and discussed the influence of water vapor formed during the reduction on the overall rate of reaction.

\section{Apparatus and Procedure}

A schematic diagram of the experimental apparatus used is shown in Fig. 1. The reactor consisted of a 25-20 stainless steel tube of $30 \mathrm{~mm}$ ID $\times 5 \mathrm{~m}$ length which was supported in a vertical position, and was heated in a vertical electric furnace consisted of six portions which were separately regulated to give a uniform temperature profile over $3.5 \mathrm{~m}$ in length. As the reducing gas, cylinder gas available in the

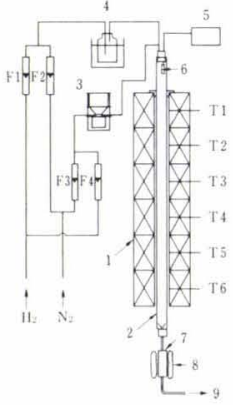

1. Furnace
2. Reactor
3. Feeder
4. $\mathrm{H}_{2} \mathrm{O}$ vapor saturator
5. Metering pump
6. Evaporator
7. Sampler
8. Mantle heater
9. Waste gas
T. Thermo-couple
F. Rotameter

Fig. 1. A schematic diagram of the gas conveyed reduction unit

* Received June 26, 1973.

** National Research Institute for Metals, Nakameguro, Meguro-ku, Tokyo 153. 
market was used in this work.

A fixed volume of reducing gas was introduced via rotameter to the ore feeder through which fine iron ores were dispersed into the reducing gas, and the residual gas was introduced to the top of the reactor as shown in Fig. 1. Reducing gas and gas-solid mixture were mixed at the top of the reactor.

In the reduction experiments with various partial pressures of water vapor, the vapor was prepared by passing the gas through a saturator kept at a certain constant temperature, and the dew point of the gas was checked at the outlet of saturator. Since the dry gas should be fed to the solid feeder, the corresponding amount of water was fed to the evaporator mounted above the reactor.

Sample trapping bottles and gas conduit pipes were heated electrically to prevent the condensation of water.

To obtain a wide range of feeding rate of fine iron ore which is dispersed in hydrogen, a feeder shown in Fig. 2 was constructed after several trials and used. It comprises a sample storage tank, a dispersing chamber, a perforated plate between them, and a vibrator. The perforated plate should have proper number and size of holes to match the required feeding rate. Fine ore was charged in the tank, the gas was led into the dispersing chamber, and then the whole system was vibrated rigorously by the vibrator.

Particle size distribution of raw materials and reduction products were measured by the sedimentgraph and the degree of reduction was estimated by the increase of weight by reoxidation.

\section{Materials}

Analytical results of pyrite cinder and Hamersley ore used as raw material are shown in Table 1. The pyrite cinder contained $57.13 \% \mathrm{~T} . \mathrm{Fe}$ and the mean particle diameter indicated by $50 \%$ pass cumurative weight was about 15 microns. The Hamersley ore contained $63.5 \% \mathrm{~T}$. Fe. The raw Hamersley ore in a form of sinter feed was crushed by a gyratory crusher and then by a ball mill. Particle size dis-

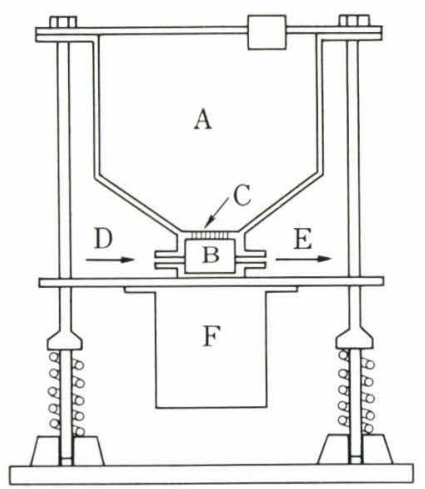

tribution of the crushed sample is shown in Fig. 3. The mean particle diameter was 18 microns.

\section{Experimental Results and Discussion}

1. Reduction of Fine Pyrite Cinder by a Gas Conveyed System

\section{Effect of Feeding Rate on Reduction}

Typical reduction curves for various feeding rates at $750^{\circ}, 850^{\circ}$, and $950^{\circ} \mathrm{C}$ are shown in Fig. 4. At $750^{\circ} \mathrm{C}$, the degree of reduction reached $38 \%$ in $4 \mathrm{sec}$ when the feeding rate is $1.41 \mathrm{~g} / \mathrm{min}$, but the rate of reduction did not decrease so much and the degree of reduction was $32 \%$ at $4 \mathrm{sec}$, when the feeding rate of ore was increased to $21.3 \mathrm{~g} / \mathrm{min}$. When the temperature was raised to $850^{\circ} \mathrm{C}$, the effect of solid feeding rate appeared at about $1.5 \mathrm{sec}$ after the reduction started, and at $4 \mathrm{sec}$, the degree of reduction at the feeding rate of $0.33 \mathrm{~g} / \mathrm{min}$ became larger by $40 \%$ than that of $11.8 \mathrm{~g} / \mathrm{min}$. For the reduction at $950^{\circ} \mathrm{C}$, the rate of reaction was hastened but the effect of solid feeding rate was comparable to the experiments made at $850^{\circ} \mathrm{C}$.

2. Relation between the Feeding Ratio of Ore/Gas and the Degree of Reduction

In the figure described above, reduction curves

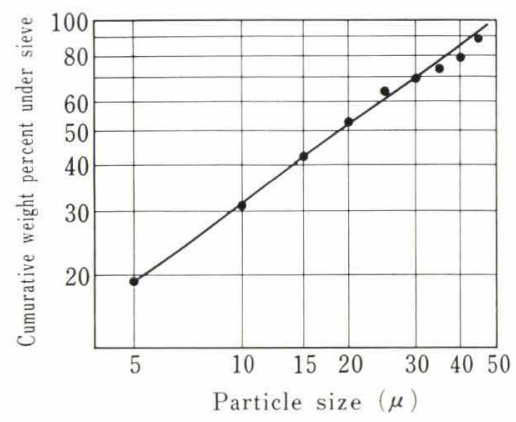

Fig. 3. Particle size distribution of fine Hamersley ore

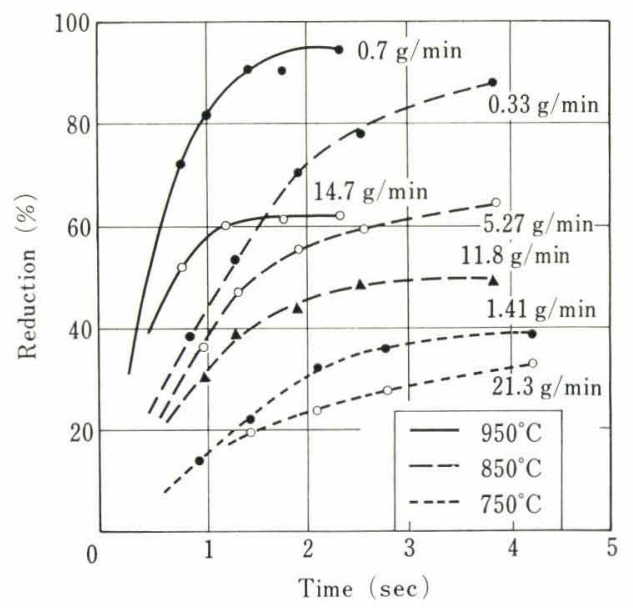

Fig. 4. Reduction of pyrite cinder at various feeding rates

Table 1. Chemical composition of iron ores (\%)

\begin{tabular}{c|c|c|c|c|c|c|c|c|c|c} 
& $\mathrm{T} . \mathrm{Fe}$ & $\mathrm{Fe}(\mathrm{II})$ & $\mathrm{CaO}$ & $\mathrm{SiO}_{2}$ & $\mathrm{Al}_{2} \mathrm{O}_{3}$ & $\mathrm{P}$ & $\mathrm{S}$ & $\mathrm{Cu}$ & $\mathrm{Zn}$ \\
\hline Pyrite cinder & 57.13 & 3.25 & 0.66 & 10.45 & 1.2 & 0.013 & 1.46 & 0.17 & 0.17 \\
\hline Hamersley ore & 63.5 & 0.62 & 0.35 & 3.62 & 2.21 & 0.052 & 0.021 & - & - \\
\hline
\end{tabular}


were simply plotted in relation to the feeding rate of ore. Thus, it is not appropreate to discuss the rate of reduction based on these curves since the feeding rate of gas was varied at each point so as to change the residence time of charge, which is regarded as the reaction time.

Then, the ratio of solid feeding rate $S(\mathrm{~g} / \mathrm{min})$ to the gas feeding rate $G(\mathrm{~N} l / \mathrm{min})$, namely $S / G$ was chosen as an index of solid concentration. Figure 5 shows the relation between the $S / G$ ratio and the degree of reduction in a series of residence time. In this figure, each intersection to the ordinate is considered to represent the reduction of single particle at the corresponding reduction time.

The higher the solid concentration is, the lower the degree of reduction results and the extent is more pronounced in a region of higher reduction. This may be due to the effect of water vapor produced in the course of reduction as discussed later.

\section{Effect of Feeding Ratio of Ore and Gas on the Reduc- tion}

For each reduction temperature, the degrees of reduction were plotted against the values of $S / G$ in the same way as that of Fig. 5 and the obtained reduction curves which are corresponding to $S / G=0,0.1$, $0.2,0.3$ are shown in Figs. 6, 7, and 8 respectively. In these figures, the reduction curves at the $S / G$ value and/or a half of which hold theoretical requirement for $\mathrm{Fe}-\mathrm{FeO}$ equilibrium to obtain $100 \%$ reduction were also shown.

Figure 6 shows the reduction curves at $750^{\circ} \mathrm{C}$. In this figure, the effect of feeding ratio on the rate of reduction is not so changed in the range from very dilute phase to the theoretical limit.

As shown in Fig. 7, there is a remarkable difference between the reaction rate in a very dilute phase and that in the theoretical limit $(S / G=0.991)$ at $850^{\circ} \mathrm{C}$. At the reduction time 4 sec., the degree of reduction reached above $90 \%$ in a very dilute phase, but it was only $50 \%$ in the case of $S / G=0.991$. At $950^{\circ} \mathrm{C}$, as shown in Fig. 8. The degree of reduction reached $97 \%$ in 2 sec for a very dilute phase, but it was only $70 \%$ even for half the value of theoretical $S / G$.

We have described about the reduction behavior in the gas conveyed system when the solid feeding rate was increased and noticed that the effect of $S / G$ on the degree of reduction was small at $750^{\circ} \mathrm{C}$ but increased at higher temperatures, $850^{\circ}$ and $950^{\circ} \mathrm{C}$. In all cases the effect of $S / G$ was small at the beginning of reduction and increased as the reduction proceeded. These phenomena may be explained as follows: the concentration of water vapor is low because of slow reaction rate at low temperature and the effect of water vapor concentration on the reaction rate becomes small, accordingly the effect of $S / G$ ratio on the rate of reduction is also small. At the beginning of reaction, because of low concentration of water vapor produced, the rates of reduction do not show a considerable difference. For instance, the concentration of water vapor in the reducing gas is only about $1.4 \%$ even for $S / G=0.3$ at the condition of $750^{\circ} \mathrm{C}$ and $4 \mathrm{sec}$ which is corresponding to the beginning stage of

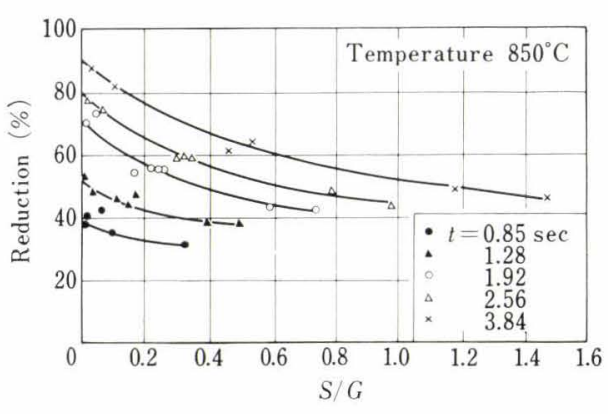

Fig. 5. Relation between the degree of reduction $(R)$ in $\%$ and the ratio of feeding rate of solid iron ore to that of gaseous reducing agent $(S / G)$

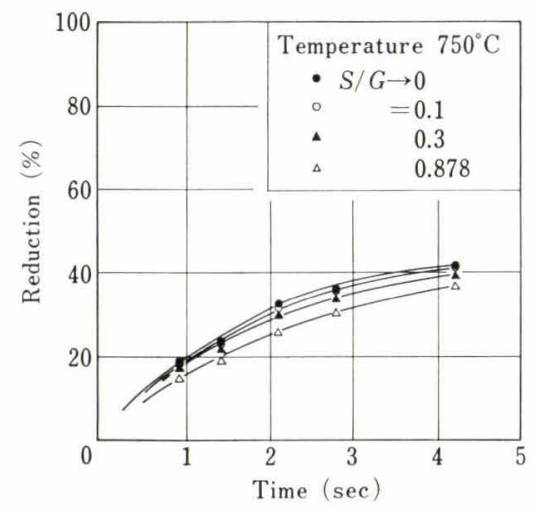

Fig. 6. Reduction of fine pyrite cinder at $750^{\circ} \mathrm{C}$

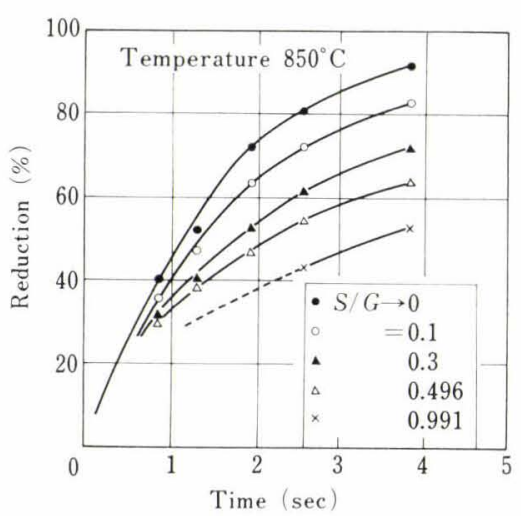

Fig. 7. Reduction of fine pyrite cinder at $850^{\circ} \mathrm{C}$

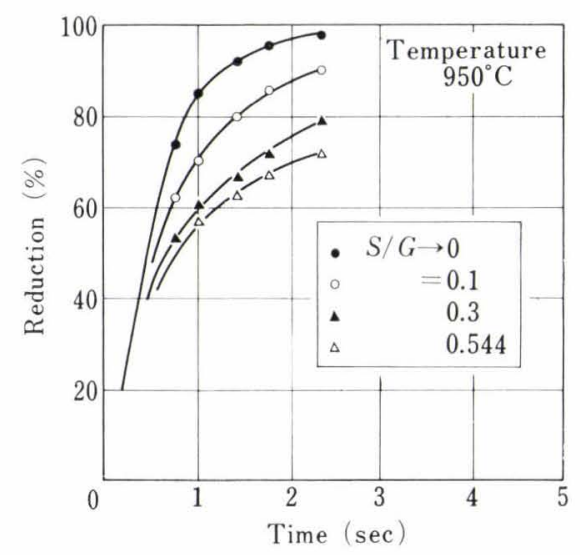

Fig. 8. Reduction of fine pyrite cinder at $950^{\circ} \mathrm{C}$

reduction. This means that the feeding ratio does not give any effect on the reduction behavior.

The gas conveyed reduction of fine iron ores may 
be utilized in the following commercial purposes:

(1) Prereduction of fine ores

(2) Production of high quality reduced sponge iron powder (high degree of reduction).

In the case (1), it may be performed even at low temperature and high feeding rate of ore, but in the case (2), high temperature and low $S / G$ ratio or multi-stage reduction are required.

\section{Process Efficiency}

In the above discussion, the ratio of solid and gas feeding rates $S / G$, was taken to specify the ore concentration. Now, let us briefly consider that to what extent the value of $S / G$ is corresponding to the processing capacity, for instance, $S / G=0.3$ in Fig. 8. As can be seen in this figure, $60 \%$ reduction is obtained in $1 \mathrm{sec}$. Since the residence time corresponds to the hydrogen gas flow of $35 \mathrm{Nl} / \mathrm{min}$, it becomes $10.5 \mathrm{~g} / \mathrm{min}$, namely $630 \mathrm{~g} / \mathrm{hr}$ in the solid feeding rate. Usual single stage experimental fluidized bed reactor having equivalent reactor volume to this system may be $8 \mathrm{~cm}$ inner diameter and $70 \mathrm{~cm}$ height. If an attempt is made to reduce this fine ore up to $60 \%$ in the above mentioned fluidized bed, the flow rate of fluidizing gas will be about $0.3 \mathrm{~N} l / \mathrm{min}$ when $20 \%$ of the terminal velocity for the mean particle size is applied as a fluidizing gas velocity. As the utilization of gas is estimated to be $30 \%$, the processing capacity will be about $25 \mathrm{~g} / \mathrm{hr}$, which is less than $1 / 20$ of the value for the gas conveyed system. Thus the gas conveyed system is more favorable than the ordinary fluidized bed in processing such fine particles.

\section{Particle Size Distribution of Reduction Products}

As it is quite probable that agglomeration may occur during high temperature reduction in a gas conveyed system by inter particle collision, a comparison between the particle size distributions of raw materials and reduction products was made. In Fig. 9, particle size distributions of raw material and reduction product of ascending flow and that of descending flow are shown. In the case of descending flow, the particle size distribution of the product shifts slightly to the larger side as compared with that of raw material, but this extent is very small. As compared with this, in the ascending flow, the size distribution curves shift considerably to the smaller side. It might be caused by the screening effect during the

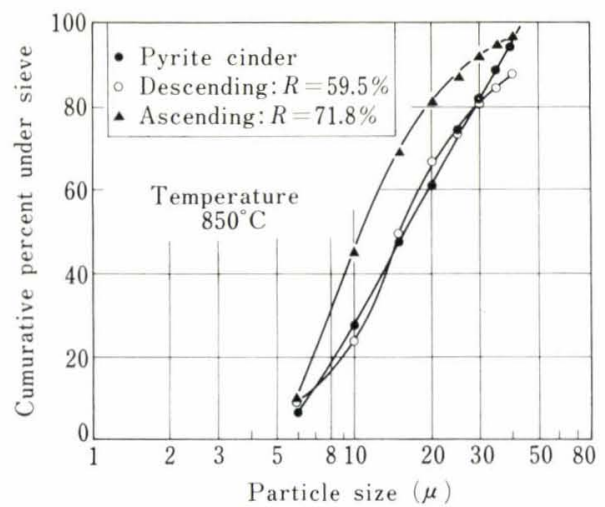

Fig. 9. Particle size distributions of fine pyrite cinder and reduction products

$R$ : reduction ascending flow and causes the fluctuation encountered in the latter experiments. Figure 10 shows the particle size distribution of the products obtained by reduction at $950^{\circ} \mathrm{C}$. Sample of higher reduction shows a little more deviation than that of lower reduction but in the descending flow, the size distribution does not change so much through the reduction.

\section{Gas Conveyed Reduction of Fine Hematite Ore}

As described above, it was recognized that the water vapor formed affects the reduction thereafter. Therefore, the effects of water vapor on the reduction were studied more quantitatively on a very dilute phase of Hamersley ore, and the relation between this effect and the reduction curves obtained by changing the ratio of $S / G$ was discussed.

\section{Relation between Partial Pressure of Water Vapor and Reduction Rate}

Reduction curves obtained at the water vapor pressure of 0 to $0.1 \mathrm{~atm}$ and $950^{\circ} \mathrm{C}$ are shown in Fig. 11 . Since the feeding rates of ore for these experiments were held under $0.3 \mathrm{~g} / \mathrm{min}$, namely $S / G<0.03$, water vapor formed during the reduction of fed ore might be permissible.

The effect brought by the addition of a small amount of water vapor was considerable; the degree of reduction decreased by half of the value at $p_{\mathrm{H}_{2} \mathrm{O}}=$ $0.1 \mathrm{~atm}$.

Before analysing the reduction data, a brief discussion on the rate equation will be made. McKewan and others have derived the rate equations based on

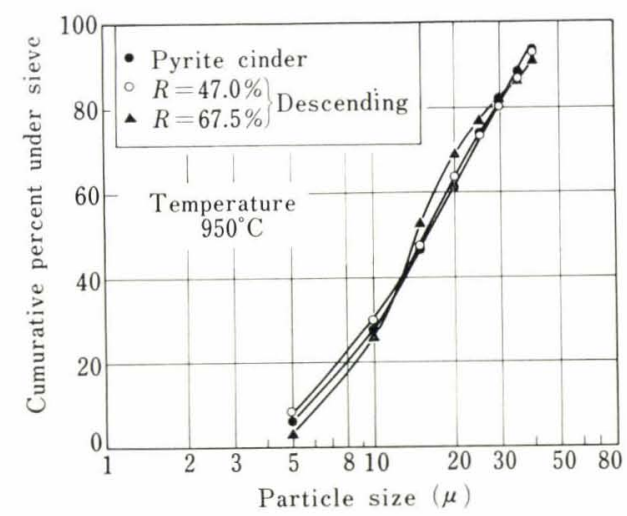

Fig. 10. Particle size distributions of fine pyrite cinder and reduction products $R$ : reduction

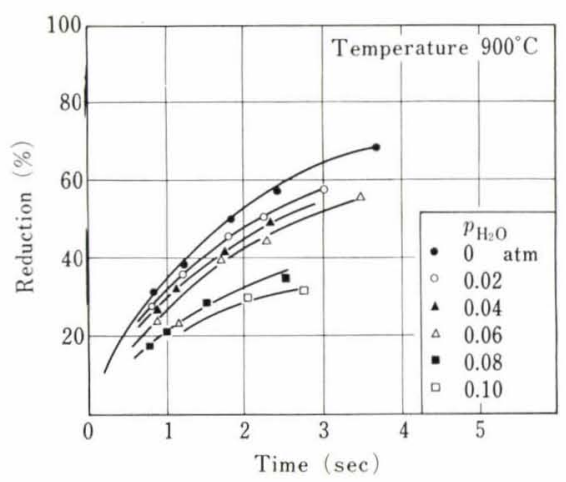

Fig. 11. Reduction of fine hematite ore in $\mathrm{H}_{2}-\mathrm{H}_{2} \mathrm{O}$ mixture 
the unreduced core model and some trials have been made to expand these equations to pellets, particles and fine powders. But as has been pointed out by Themelis et al., fine powder shows a fairly different reduction behavior as compared with the case of coarse particles. Besides, analysis is not so easy for the particles having a wide size distribution and it has therefore been almost untouched.

Thus, in this report we shall not deal precisely with the detailed mechanism but only take as an apparent rate of $n$-th order reaction, namely

$$
d R / d t=k(1-R)^{n}
$$

where, $R$ : degree of reduction, $t$ : time, $k$ : rate constant.

By integrating it,

$$
\begin{array}{ll}
1-(1-R)^{1-n}=(1-n) k t & \text { for } n \neq 1 \\
-\ln (1-R)=k t & \text { for } n=1
\end{array}
$$

In these equations

$n=2 / 3$ : corresponds to the chemical reaction control

$n=1$ : first order reaction, which has been adopted in some reports on the fluidized bed $^{6,7)}$

$n=0$ : there is some reports on the application to the fluidized bed reduction. ${ }^{8,9)}$

In the hydrogen gas conveyed reduction of fine Hamersley ore, a linear relation was observed in the plots of $R /(1-R)$ vs $t$, so the analysis was made by assuming a second order reaction. Thus, the rate equation may be formulated as

$$
R /(1-R)=k t
$$

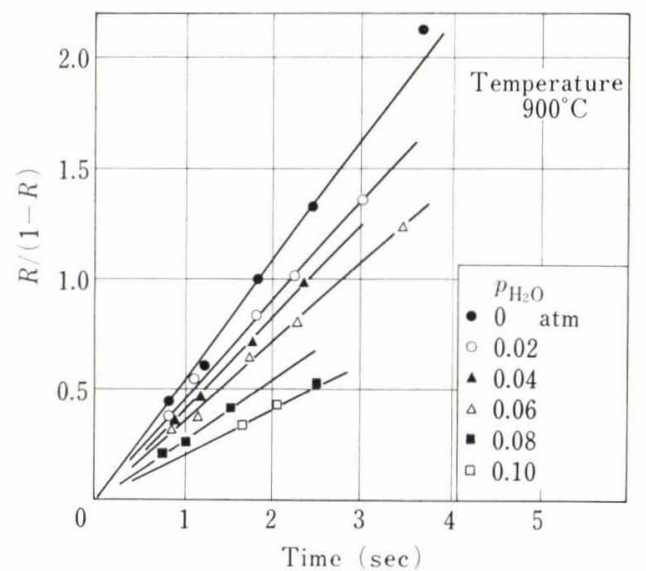

Fig. 12. Relation between $R /(1-R)$ and $t$ for various $\mathrm{H}_{2} \mathrm{O}$ partial pressures

Table 2. Values of $1 / f$ and corresponding equilibrium values for $\mathrm{FeO} / \mathrm{Fe}$

\begin{tabular}{c|c|c}
\hline $\begin{array}{c}\text { Temperature } \\
\left({ }^{\circ} \mathrm{C}\right)\end{array}$ & $1 / f$ & $\begin{array}{c}\text { Equilibrium value } \\
\text { for } \mathrm{FeO} / \mathrm{Fe}^{*}\end{array}$ \\
\hline 900 & 0.161 & 0.381 \\
800 & 0.158 & 0.347 \\
700 & 0.155 & 0.316 \\
\hline
\end{tabular}

* Calculated from equilibrium constants of Emett \& Shultz. where, $k$ : rate constant.

The effect of $p_{\mathrm{H}_{2} \mathrm{O}}(0$ to $0.1 \mathrm{~atm})$ on the reduction curve at $900^{\circ} \mathrm{C}$ is shown in Fig. 11 and the relation between $R /(1-R)$ and reduction time for the above experiment is shown in Fig. 12.

As shown above, a relatively good linearity was obtained. Through the reduction experiments at temperatures $800^{\circ}$ and $700^{\circ} \mathrm{C}$, and $p_{\mathrm{H}_{2} \mathrm{O}}: 0$ to $0.1 \mathrm{~atm}$, similar relations were obtained and the rate constants obtained were plotted against the value of $p_{\mathrm{H}_{2} \mathrm{O}}$ and are shown in Fig. 13. The rate constants decrease with increasing $p_{\mathrm{H}_{2} \mathrm{O}}$ and the relation may be formularized as follows :

$$
\text { At } \begin{array}{rlrl}
900^{\circ} \mathrm{C} & k & =0.540\left(1-6.20 p_{\mathrm{H}_{2} \mathrm{O}}\right) \\
800^{\circ} \mathrm{C} & k=0.285\left(1-6.32 p_{\mathrm{H}_{2} \mathrm{O}}\right) \\
700^{\circ} \mathrm{C} & k=0.160\left(1-6.44 p_{\mathrm{H}_{2} \mathrm{O}}\right)
\end{array}
$$

and their general form is given by

$$
k=k_{0}\left(1-f p_{\mathrm{H}_{2} \mathrm{O}}\right)
$$

In this equation, $1 / f$ corresponds to the partial pressure of water vapor whereat no more reduction proceeds and has the values shown in Table 2. These values are rather small relative to the equilibrium value for $\mathrm{FeO} / \mathrm{Fe}$. This may be caused by the facts that the reaction occurred in a very short period of time and that the data were extrapolated to a higher range of $p_{\mathrm{H}_{2} \mathrm{O}}$.

Arrhenius' plots for the experiments made at $p_{\mathrm{H}_{2} \mathrm{O}}=0$ to $0.08 \mathrm{~atm}$ showed a fairly good linearity and gave an apparent activation energy of 13.2 to $13.7 \mathrm{kcal} / \mathrm{mol}$, which is in good agreement with the value of $13.8 \mathrm{kcal} / \mathrm{mol}$ obtained by McKewan. ${ }^{10)}$

\section{Reduction Rate for Various $\mathbf{S} / \mathbf{G}$ (Effect of $\mathbf{S} / \mathbf{G}$ on the}

\section{Reduction Rate)}

Based on the experimental results obtained by changing the ratio $S / G$, the degrees of reduction, $R$, for the same residence time were plotted against the values of $S / G$, and the reduction curves for $S / G=0.1$, 0.2 and 0.3 are shown in Fig. 14. In this case, the ratio $S / G$ does not affect the reaction rate at the beginning of reduction, but the effect becomes apparent as the reaction proceeds. As shown in Figs. 15 and 16 , a similar tendency was observed in the reduction curves at $800^{\circ}$ and $700^{\circ} \mathrm{C}$.

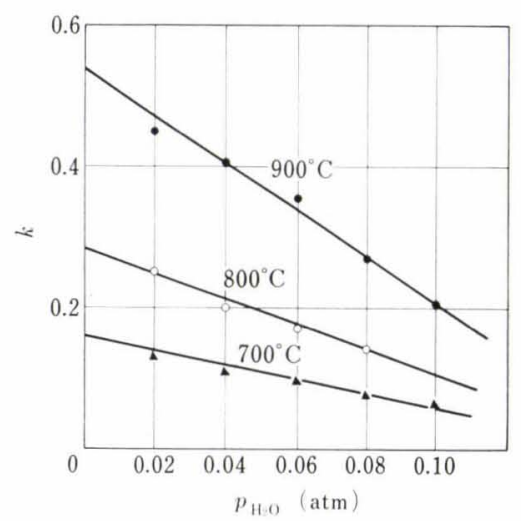

Fig. 13. Relation between reduction rate constant $k$ and partial pressure of $\mathrm{H}_{2} \mathrm{O}$ 


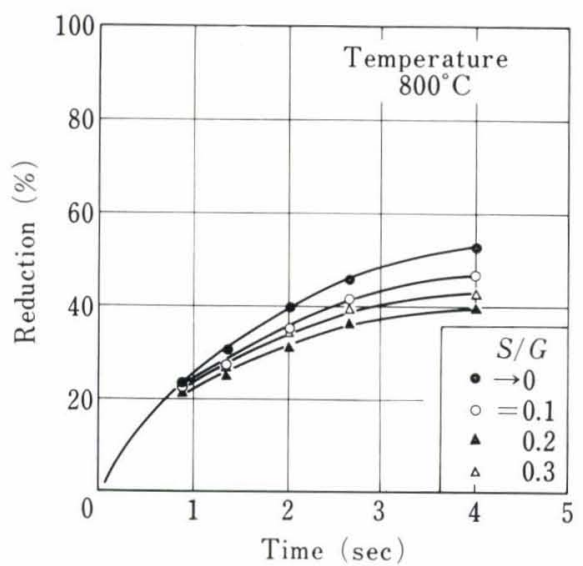

Fig. 14. Reduction for various $S / G$ at $900^{\circ} \mathrm{C}$

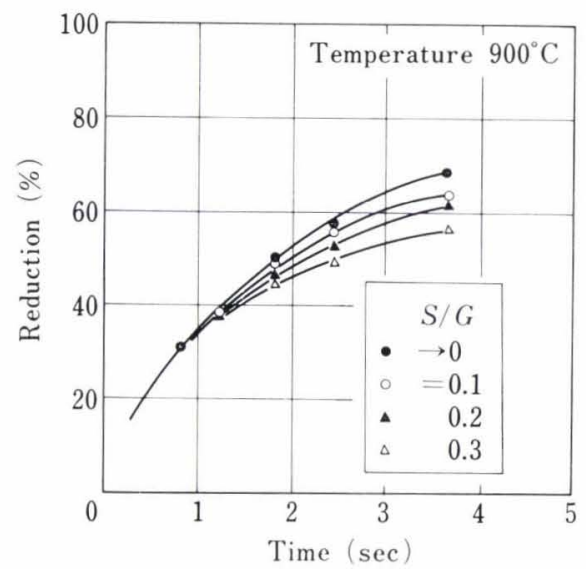

Fig. 15. Reduction for various $S / G$ at $800^{\circ} \mathrm{C}$

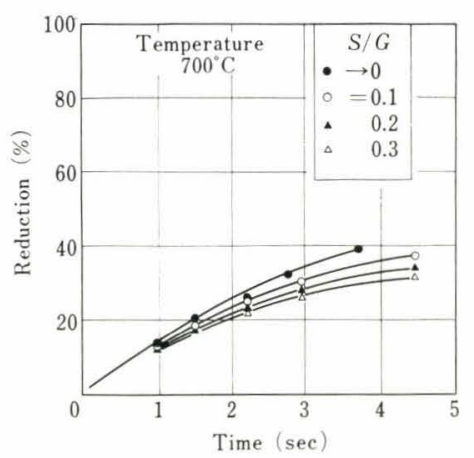

Fig. 16. Reduction for various $S / G$ at $700^{\circ} \mathrm{C}$

As the ratio $S / G$ increased in a dense phase of gas transport, the gas-solid reaction is hindered by water vapor, which is formed by the reducing reaction and accumulated during the transport through the tube. For such a process, the following overall rate equation can be derived.

First of all we have postulated a plug flow to the gas-solid mixture and no slip in the solid movement to the gas flow.

If $S / G=a(\mathrm{~g} / l)$

oxygen removed by reduction per $1 \mathrm{~g}$ of ore : $b(-)$

oxygen originally contained in $1 \mathrm{~g}$ of ore : $d(-)$ the degree of reduction $R$ (in fraction) can be expressed as follows :

$$
R=b / d
$$

Since the reducing reaction is

$$
\mathrm{FeO}+\mathrm{H}_{2}=\mathrm{Fe}+\mathrm{H}_{2} \mathrm{O}
$$

the number of moles of water formed at the degree of reduction $R$ is

$$
a b / 16=a d R / 16
$$

If the mole fraction of water vapor is used, it becomes

$$
\begin{aligned}
x_{\mathrm{H}_{2} \mathrm{O}} & =p_{\mathrm{H}_{2} \mathrm{O}} /\left(p_{\mathrm{H}_{2}}+p_{\mathrm{H}_{2} \mathrm{O}}\right) \\
& =(a d R / 16) /(1 / 22.4)
\end{aligned}
$$

From the experimental condition,

then,

$$
p_{\mathrm{H}_{2}}+p_{\mathrm{H}_{2} \mathrm{O}}=1
$$

$$
\begin{aligned}
& p_{\mathrm{H}_{2} 0}=(22.4 / 16) a d R \\
& =\mathrm{cad} R
\end{aligned}
$$

where, $c=22.4 / 16$.

Thus, when ore is reduced to a certain degree of reduction, $R$, in a gas conveyed system, the partial pressure of water vapor at this point is represented by Eq. (2).

As has been described previously, the following relations are confirmed experimentally,

$$
\begin{aligned}
& d R / d t=k(1-R)^{2} \ldots \\
& k=k_{0}\left(1-f p_{\mathrm{H}_{2} 0}\right) \ldots
\end{aligned}
$$

thus,

$$
\begin{aligned}
d R / d t & =k_{0}(1-f a c d R)(1-R)^{2} \\
& =k_{0}(1-\alpha R)(1-R)^{2} \\
\alpha & =\text { facd }
\end{aligned}
$$

The integrated form of this rate equation is

$$
\begin{aligned}
& \int_{0}^{R} \frac{d R}{(1-\alpha R)(1-R)^{2}}=k_{0} \int_{0}^{t} d t \ldots \ldots . . \\
& \quad R \quad+\frac{\alpha}{1-\alpha} \ln \frac{1-R}{1-\alpha R}=k_{0}(1-\alpha) t
\end{aligned}
$$

This equation may be rearranged to

$$
\begin{aligned}
& \frac{R}{1-R}+\beta \log \frac{1-R}{1-\alpha R}=k^{\prime} t \\
& \beta=\frac{1}{0.4343}\left(\frac{\alpha}{1-\alpha}\right) \\
& k^{\prime}=k_{0}(1-\alpha)
\end{aligned}
$$

As formularized above, if the rate equation is given as Eq. (3) for a very dilute solid gas mixture in the gas conveyed system, and if the effect of water vapor is expressed by Eq. (4), the effect of water vapor appeared when $S / G$ is increased may be given in a term of

$$
\beta \log \frac{1-R}{1-\alpha R}
$$

In Eq. (8), $\alpha$ and $\beta$ are the constants determined from the value of $S / G$ and experimental temperature. From Fig. 17 which is showing the relation of Eq. (8) for $S / G=0.1,0.2$, and 0.3 at $900^{\circ} \mathrm{C}$, it is obvious that 


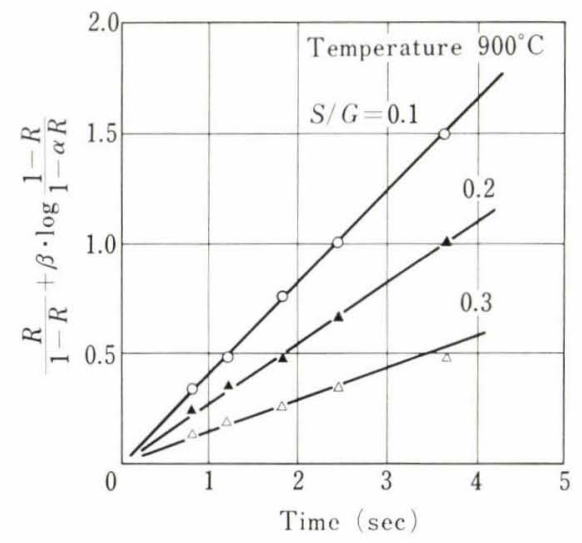

Fig. 17. Relation between $R /(1-R)+\beta \log [(1-R) /(1-\alpha R)]$ and $t$ at $900^{\circ} \mathrm{C}$

Table 3. Constants for the equation;

$$
R /(1-R)+\beta \log [(1-R) /(1-\alpha R)]=k^{\prime} t
$$

\begin{tabular}{c|c|c|c|c}
\hline Temperature & $a$ & $\alpha$ & $\beta$ & $k^{\prime}$ \\
\hline \multirow{3}{*}{$900^{\circ} \mathrm{C}$} & 0.1 & 0.244 & 0.744 & 0.408 \\
& 0.2 & 0.488 & 2.20 & 0.276 \\
& 0.3 & 0.732 & 6.29 & 0.145 \\
\hline \multirow{3}{*}{$800^{\circ} \mathrm{C}$} & 0.1 & 0.249 & 0.765 & 0.214 \\
& 0.2 & 0.498 & 2.29 & 0.143 \\
& 0.3 & 0.747 & 6.80 & 0.0721 \\
\hline \multirow{2}{*}{$700^{\circ} \mathrm{C}$} & 0.1 & 0.253 & 0.781 & 0.120 \\
& 0.2 & 0.506 & 2.36 & 0.079 \\
& 0.3 & 0.759 & 7.25 & 0.0386
\end{tabular}

the experimental result verifies the above derivation. Constants for Eq. (8) are given in Table 3.

\section{Conclusions}

As a study on the gas conveyed reduction of fine iron ore, hydrogen gas conveyed reduction of fine pyrite cinder was investigated by increasing the concentration of solid and the following results were obtained.

(1) Reduction of fine pyrite cinder, which is very difficult to reduce in the ordinal fluidized bed process, was successful with a fairly good efficiency of reactor volume.

(2) At a relatively low temperature, $\left(750^{\circ} \mathrm{C}\right)$ the feeding rate did not show any remarkable effect on the reduction rate but the effect of feeding rate increased when the temperature was risen to $850^{\circ}$ and $950^{\circ} \mathrm{C}$. Consequently, high temperature reduction with a small $S / G$ ratio is necessary to obtain a high degree of reduction in one stage.

(3) Considerable shift in the particle size distribution was not observed for the descending flow gas conveyed system, within the experimental conditions adopted.

Besides the above experiments, fine hematite ore was reduced in the gas conveyed system. Effect of water vapor on the rate of reduction was examined and the rate of reduction at increased feeding rates of solid was studied. A rate equation was derived by considering the effect of water vapor produced during the reduction process. The results obtained are :

(4) Gas conveyed reduction of fine Hamersley ore seemed to proceed apparently as a second order reaction when the concentration of solid was dilute, and the relation between the rate constant and $p_{\mathrm{H}_{2} \mathrm{O}}$ was formularized in a linear equation.

(5) Considering the effect of water vapor produced during the reduction in an elevated concentration of ore, the overall rate equation may be expressed by

$$
\frac{R}{1-R}+\beta \log \frac{1-R}{1-\alpha R}=k t
$$

and this equation agreed quite well with the experimental results.

\section{Acknowledgements}

The authors wish to express their appreciation to I. Inoguchi and N. Suzuki for trial built of the apparatus in which fine ore is dispersed in the reducing gas.

\section{REFERENCES}

1) D. Kunii: Ryūdōkahō, (1962), 49, Nikkan Kōgyō Press, Tokyo.

2) W. A. Lloyd and N. R. Amundson: Ind. Eng. Chem., 53 (1961), 19

3) I. G. Dalla Lana and N. R. Amundson: Ind. Eng. Chem., 53 (1961), 22.

4) N.J. Themelis and W. H. Gauvin: AIChEJ, 8 (1962), 437.

5) M. Tanaka and M. Ozawa: Tetsu-to-Hagané, 53 (1967), 1168.

6) A. Ōkura and Y. Matsushita: Tetsu-to-Hagané, 50 (1964), 159.

7) H. P. Meisner and F. C. Shora: Trans. AIME, 221 (1961), 1221.

8) S. Y. Ezz and R. Wild: JISI, 194 (1960), 211

9) M. Ozawa and M. Tanaka: Tetsu-to-Hagané, 52 (1966), 1317.

10) W. M. Mckewan: Trans. AIME, 224 (1962), 2. 